\title{
A evolução da deformação piroplástica de porcelanatos durante a queima
}

\author{
Lisandra R. dos Santos ${ }^{a}$, Suelen Nastria,b, Suelen Zenattia, Ana Virgínia Lot ${ }^{\mathrm{b}}$, Fábio G. Melchiades ${ }^{a}$, \\ Anselmo O. Boschib. \\ ${ }^{a}$ Centro Revestimentos Cerâmicos - CRC, São Carlos, SP, Brasil

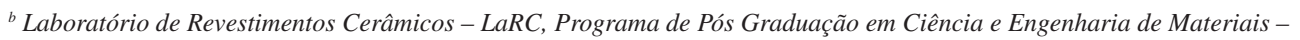 \\ PPGCEM, Universidade Federal de São Carlos - UFSCar, São Carlos, SP, Brasil. \\ *anselmo.ufscar@gmail.com
}

\begin{abstract}
Resumo
O desenvolvimento de novos produtos de grandes dimensões e espessuras reduzidas tem tornado cada vez mais difícil o controle da planaridade dos porcelanatos. O método tradicional para a quantificação da tendência das massas à deformação piroplástica é baseado na deformação final dos produtos. Entretanto, para que se possa atuar com mais propriedade sobre a formulação das massas e as condições de fabricação é importante saber como a peça se deforma durante a queima até chegar à deformação final. O flexímetro ótico permite registrar continuamente a deformação das peças durante a queima. Além disso, a precisão da medida da deformação é consideravelmente maior do que no método tradicional. Nesse contexto o objetivo desse trabalho foi utilizar essa tecnologia, flexímetro ótico, para acompanhar continuamente a evolução das deformações de massas industriais de porcelanato durante a queima e identificar as principais alternativas para a diminuição das mesmas. Observou-se que a maior parte das deformações sofridas pelas placas ocorre na máxima temperatura de queima e que ciclos com menores tempos de patamar contribuem para a redução dos defeitos de planaridade. Nesse sentido, constatou-se, ainda, que menores resíduos de moagem, maior densidade aparente do compacto verde e composições que favorecem a formação de fases líquidas mais viscosas em elevadas temperaturas também contribuem para a redução das deformações piroplásticas.
\end{abstract}

Palavras chave: deformação piroplástica, porcelanatos, flexímetro ótico, índice de piroplasticidade.

\section{Introdução}

Enquanto a produção de revestimentos cerâmicos permaneceu na faixa dos 800 milhões de metros quadrados nos últimos anos, a produção de porcelanatos apresentou um crescimento expressivo, atingindo 140 milhões de metros quadrados em 2018. Isso sugere que empresas que, usualmente, buscavam incrementar sua capacidade produtiva de revestimentos pela rota de via seca, estão, mais recentemente, diversificando suas produções investindo na fabricação de produtos com maior valor agregado, o porcelanato.

Para garantir o alto desempenho técnico desses produtos, os mesmos devem apresentar porosidade bastante reduzida. Esta é alcançada através de queima em temperaturas relativamente altas para que uma elevada quantidade de fase líquida se forme e preencha os poros existentes no compacto verde [1]. Como consequência, intensifica-se a tendência à deformação piroplástica para essa tipologia de produto.

Entende-se por deformação piroplástica os desvios permanentes na planaridade das peças que ocorrem em temperaturas elevadas devido à ação da gravidade. [2]

Tais desvios podem se manifestar de diferentes modos, como ilustrado na Figura 1, originando defeitos como ondulações na placa e pontas caídas ou levantadas, por exemplo.
A dificuldade do controle da planaridade dos porcelanatos se tornou ainda mais crítica devido a atual tendência de placas cada vez maiores, as chamadas lastras, com espessuras reduzidas. Cabe, ainda, mencionar a tendência crescente na produção de porcelanatos polidos e lapados (esmaltados polidos). Nesse tipo de superfície, o reflexo especular torna qualquer deformação facilmente perceptível, prejudicando justamente o aspecto espelhado que faz com que esses produtos sejam tão valorizados.

Nesse cenário, a preocupação com o controle de deformações das peças durante a queima é cada vez mais essencial na indústria cerâmica.

No desenvolvimento de um produto, o Índice de Piroplasticidade - IP - é a ferramenta utilizada para quantificar as deformações piroplásticas sofridas pelo revestimento. $\mathrm{O}$ método tradicional para se determinar essa característica consiste em posicionar um corpo de prova de $6 \times 2 \mathrm{~cm}$ sobre dois apoios e submeter o conjunto ao ciclo de queima típico, como ilustra a Figura 2. A partir da medida da flecha da curvatura do corpo de prova após a queima (S), da sua espessura (h) e da distância entre os apoios (L), determina-se o Índice de Piroplasticidade (IP), em cm-1 $\mathrm{cm}^{-1}$ através da Equação 1. 

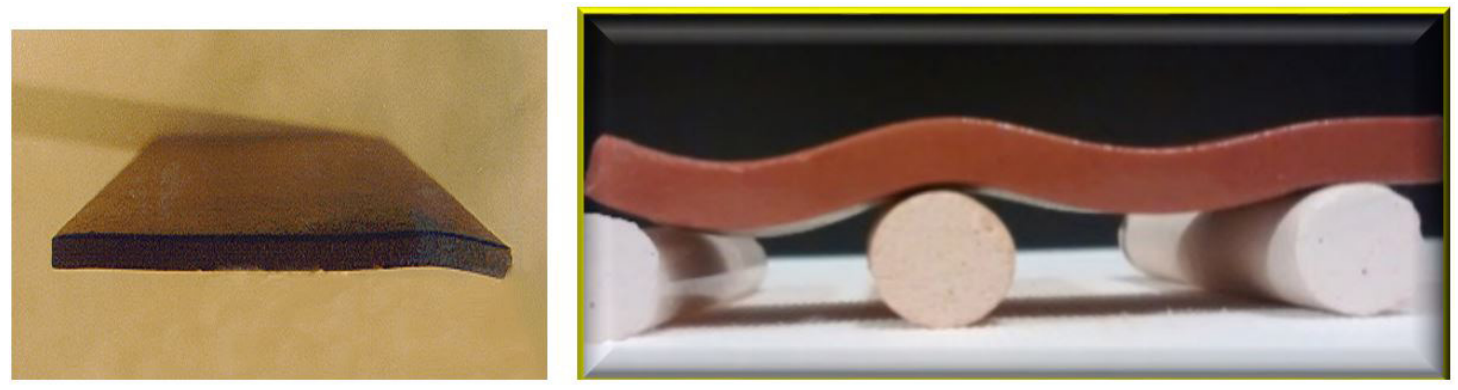

Figura 1 - Defeitos na planaridade de porcelanatos [Fonte: Autor]

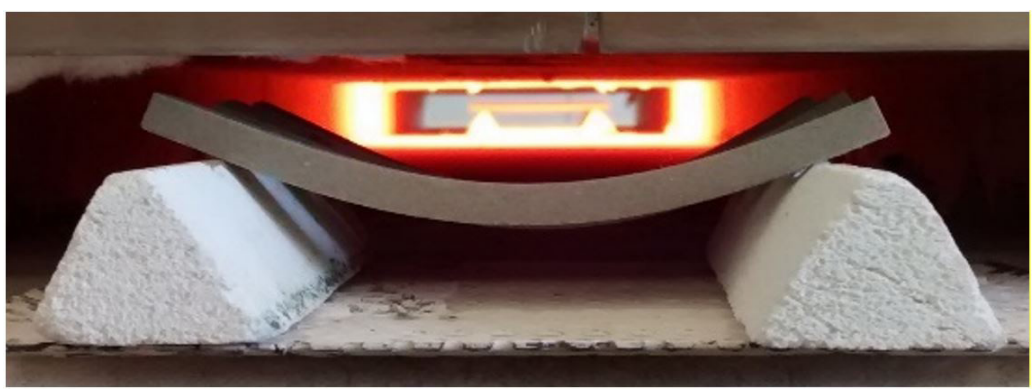

Figura 2 - Ensaio para determinação do Índice de Piroplasticidade - IP [Fonte: Autor].

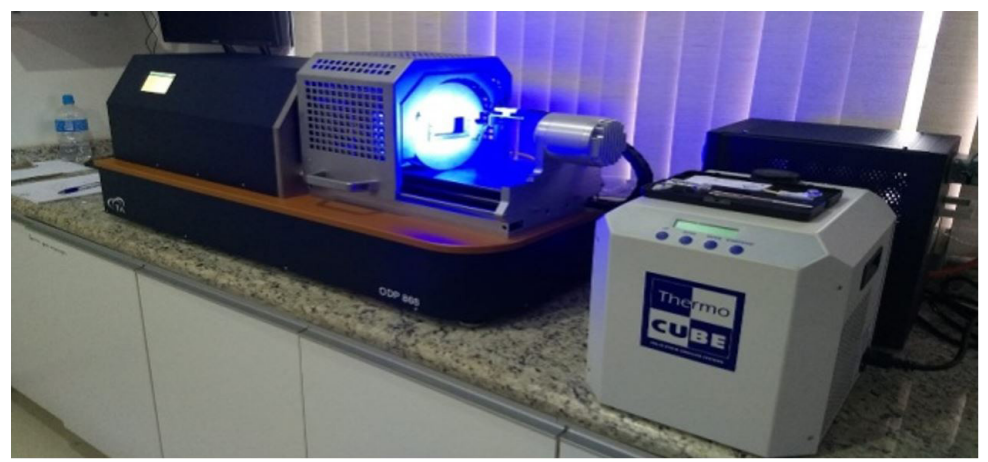

Figura 3 - Flexímetro ótico [Fonte: Autor].

$$
I P=\frac{4 \cdot h^{2} \cdot S}{3 \cdot L^{4}} \quad \text { Equação } 1 \text { [3]. }
$$

O método tradicional para a quantificação da tendência das massas à deformação piroplástica é baseado na deformação final dos produtos. Entretanto, para que se possa atuar com mais propriedade sobre a formulação das massas e as condições de fabricação é importante saber como a peça se deforma durante a queima até chegar à deformação final. O flexímetro ótico - Figura 3 - é um sistema ótico constituído por lentes de elevada resolução que permite a detecção de variações dimensionais de até $0,02 \mu \mathrm{m}$. Além disso, o equipamento opera dentro de um forno capaz de trabalhar, com segurança, com taxas de aquecimento de até $50^{\circ} \mathrm{C}$ por minuto e atinge temperaturas de até $1600^{\circ} \mathrm{C}$. Dessa forma, ciclos de queima rápidos podem ser realizados e acompanha-se toda a cinética da deformação sofrida pelo corpo cerâmico durante esse processo, em função do tempo e da temperatura.

Nesse cenário, o objetivo do trabalho foi utilizar o flexímetro ótico para acompanhar a evolução, durante a queima, das deformações piroplásticas de massas típicas de porcelanato e identificar as principais alternativas pra manter essa característica dentro de limites aceitáveis.

\section{Materiais e métodos}

Em vista do objetivo definido, o trabalho foi dividido em duas etapas:

- Etapa 1: acompanhamento das deformações sofridas por massas típicas de porcelanato durante a queima.

- Etapa 2: avaliação dos efeitos de variáveis industriais sobre a deformação piroplástica. 
Na Etapa 1, as deformações sofridas por corpos de prova produzidos a partir de composições típicas de porcelanato foram acompanhadas pelo flexímetro ótico. A Figura 4 apresenta, em detalhe, a montagem experimental do teste realizado. Os corpos de provas de $85 \mathrm{~mm}$ de comprimento e seção transversal de $5 \times 5 \mathrm{~mm}$, foram posicionados sobre dois anéis de apoio, separados por uma distância de $70 \mathrm{~mm}$. A seguir, os corpos de provas foram submetidos a um ciclo de queima pré-definido e as deformações foram registradas.

As deformações após a queima se devem ao fluxo viscoso do líquido formado a temperaturas elevadas, o que, segundo a literatura, depende fundamentalmente de três fatores:

- o volume de fase líquida formada,

- as características da fase líquida, principalmente sua viscosidade, $\mathrm{e}$

- a densidade aparente da peça, que estabelece o volume de poros disponível para alojar o líquido, devendo ser preenchido quase que em sua totalidade para que a absorção de água próxima de zero seja atingida.

Na Etapa 2 algumas variáveis de processo foram alteradas e os efeitos dessas alterações foram determinados.

\section{Resultados}

\section{Etapa 1: Deformações de massas típicas de porcelanato durante a queima.}

A Figura 5 apresenta um exemplo de resultado obtido com o ensaio realizado no flexímetro ótico para uma massa típica de porcelanato. Diferentemente do método tradicional, neste equipamento, é possível acompanhar continuamente a deformação sofrida pelo corpo de prova, em mícrons $(\mu \mathrm{m})$, durante a queima, como representa a curva azul. Nota-se que, durante a queima, a parte central do corpo de provas se deslocou $2200 \mu \mathrm{m}$ para baixo, em relação ao seu plano original, devido à ação da gravidade. A curva vermelha apresenta a variação da temperatura, representada no outro eixo do gráfico. Essa é a representação como medida pelo equipamento que mede independentemente essas duas variáveis, a deformação, através de um sistema ótico de alta precisão, e a temperatura, através de um termopar próximo ao corpo de prova. A Figura 6 apresenta outra forma de representação das informações contidas na Figura 5, a variação do índice de piroplasticidade durante a queima. Esta forma de representação é, sob o ponto de vista de visualização das alterações durante a queima, mais amigável e útil.

Pode-se notar na Figura 6 que até $1100^{\circ} \mathrm{C}$ o IP varia muito pouco e que acima dessa temperatura o mesmo aumenta muito rapidamente até atingir a máxima temperatura de queima a $1215^{\circ} \mathrm{C}$. Durante o resfriamento o IP praticamente não varia e é comum encerrar a medida a $600^{\circ} \mathrm{C}$. Ou seja, neste caso específico, pode-se dizer que a praticamente toda a deformação piroplástica ocorre entre $1100 \mathrm{e} 1215^{\circ} \mathrm{C}$. Com base na literatura pode-se dizer que

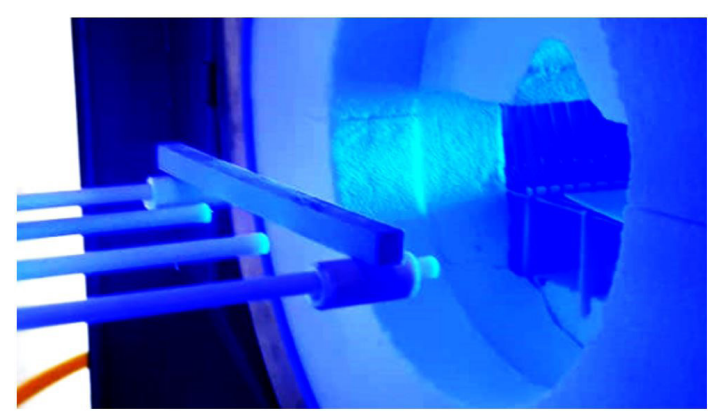

Figura 4 - Corpo de prova posicionado sobre apoio para o ensaio no flexímetro ótico [Fonte: Autor].

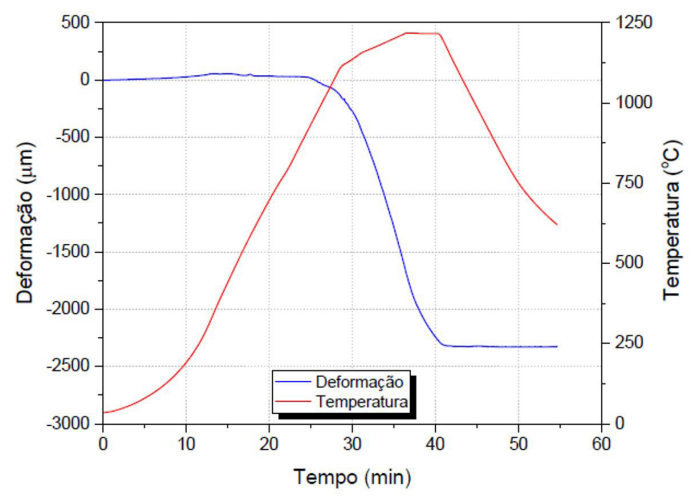

Figura 5 - Deformação sofrida pelo corpo de prova e temperatura do forno em função do tempo de ensaio.

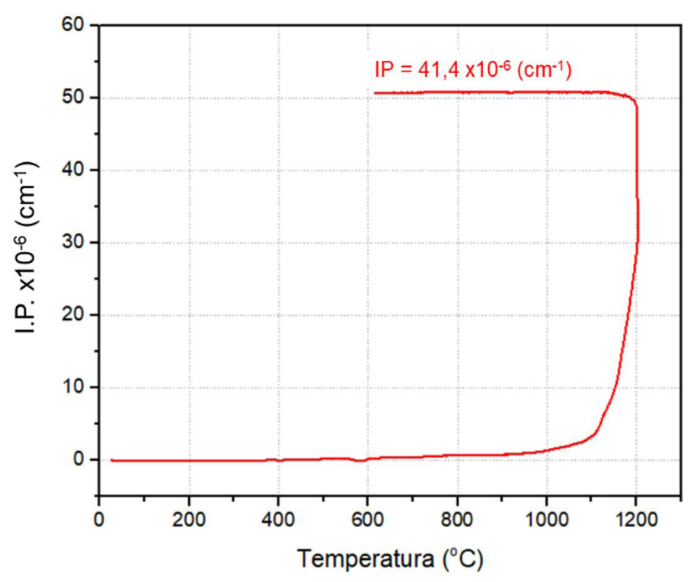

Figura 6 - Variação do índice de piroplasticidade (IP) durante a queima.

a principal causa desse comportamento é o surgimento de um apreciável volume de fase líquida a $1100^{\circ} \mathrm{C}$ e que esse volume aumenta e a viscosidade da mesma diminui com o aumento da temperatura.

A Tabela 1 apresenta as mesmas informações das Figuras 5 e 6 na forma de tabela.

Cabe destacar que a medida precisa e contínua da deformação da peça permite reproduzir o que acontece no 
Tabela 1. Deformação e IP da massa ao longo do ciclo térmico.

\begin{tabular}{|c|c|c|c|c|}
\hline Temperatura & Tempo & Deformação & IP & Deformação total \\
\hline$\left({ }^{\circ} \mathrm{C}\right)$ & $(\min )$ & $(\mu \mathrm{m})$ & $\left(\times 10^{-6} \mathrm{~cm}^{-1}\right)$ & $(\%)$ \\
\hline 1100 & 28,4 & $-118,6$ & 1,9 & 5 \\
\hline 1125 & 29,4 & $-204,9$ & 3,2 & 9 \\
\hline 1150 & 30,8 & $-379,8$ & 6 & 16 \\
\hline 1160 & 31,5 & $-499,9$ & 7,9 & 22 \\
\hline 1170 & 32,4 & $-683,9$ & 10,7 & 29 \\
\hline 1180 & 33,3 & $-873,8$ & 13,7 & 38 \\
\hline 1190 & 34,1 & $-1073,8$ & 16,9 & 46 \\
\hline 1200 & 35 & $-1277,8$ & 20,1 & 55 \\
\hline 1210 & 35,8 & $-1500,1$ & 23,6 & 65 \\
\hline 1215 & 36,2 & $-1612,8$ & 25,3 & 69 \\
\hline 1215 & 40,4 & $-2277,7$ & 35,8 & 98 \\
\hline Resfriamento final & 54,7 & $-2320,9$ & 36,5 & 100 \\
\hline
\end{tabular}

forno industrial durante a queima e não, como no método convencional, avaliar somente a deformação final. Dessa forma pode-se avaliar mais detalhadamente os efeitos das alterações das condições de processamento sobre a deformação piroplástica, como será visto na Etapa 2 deste.

Considerando que a variação da absorção de água e do índice de piroplasticidade durante a queima são de grande interesse para os fabricantes de porcelanato e que essas características estão relacionadas, pois ambas dependem do volume e das características da fase líquida, corpos de provas de uma massa de porcelanato técnico foram queimados a diferentes temperaturas e analisou-se a evolução da sua absorção de água e do índice de piroplasticidade. Esses resultados são apresentados na Figura 7.

Essa sequência de curvas ilustra o dilema vivido pelos ceramistas na fabricação de porcelanatos. A presença de um volume significativo de fase líquida de baixa viscosidade é necessária para se atingir a baixa absorção de água requerida por essa tipologia de produto. Por outro lado, a presença dessa fase líquida é responsável pela deformação piroplástica das peças. Nesse contexto é que o flexímetro ótico permite identificar melhor e com mais precisão os efeitos das variáveis de processamento sobre a deformação piroplástica das peças e, consequentemente, a planaridade de seus produtos.

\section{Etapa 2: estudo das variáveis controláveis industrialmente para a redução de deformações.}

Efeitos da curva de queima

A Figura 8 apresenta a evolução do IP para uma determinada massa queimada em duas temperaturas. Também estão representadas no gráfico, sobre as barras referentes a cada temperatura, o percentual da deformação final já manifestada pela peça até esse estágio. Nota-se que, independentemente da máxima temperatura de queima, aproximadamente metade da deformação total sofrida pela peça se desenvolve durante o patamar de queima. Para a massa queimada a $1200^{\circ} \mathrm{C}$, até essa temperatura o corpo de prova havia sofrido $48 \%$ da deformação final, sendo que os outros $52 \%$ ocorreram durante o patamar.

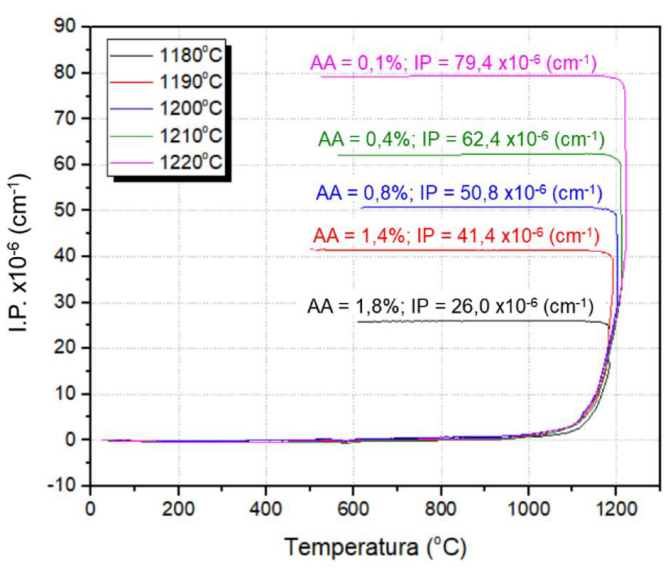

Figura 7 - Deformação sofrida, absorção de água e IP para porcelanato queimado em distintas temperaturas.

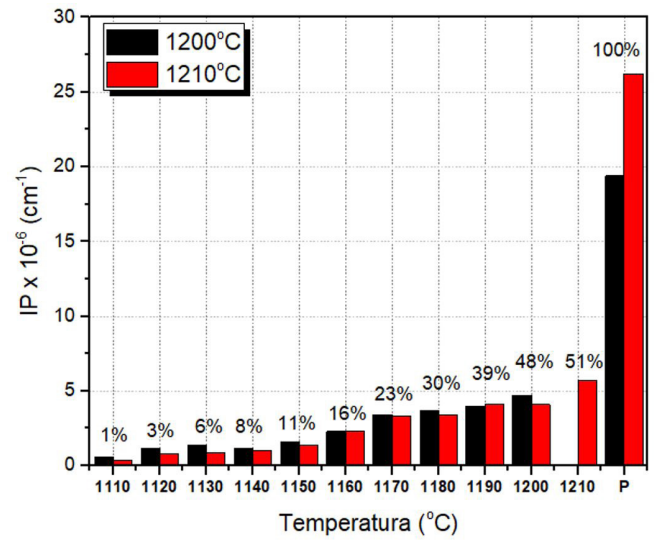

Figura 8 - IP durante o ciclo de queima de uma massa de porcelanato queimada a $1200^{\circ} \mathrm{C}$ e $1210^{\circ} \mathrm{C}$.

Para a massa queimada a $1210^{\circ} \mathrm{C}$, até essa temperatura $51 \%$ das deformações da peça já haviam se manifestado. No entanto, é no patamar de queima que o restante de $49 \%$ da deformação total é sofrido pela peça. 
Com base nesses resultados, almejando-se absorção de água inferior a $0,5 \%$ para uma massa de porcelanato esmaltado, três diferentes curvas de queima foram projetadas. Como apresentado na Figura 9, utilizaram-se três diferentes temperaturas de queima. Para a mais elevada, $1215^{\circ} \mathrm{C}$, um menor tempo de patamar, de apenas 1 minuto (barras pretas), pôde ser utilizado, o que caracteriza uma típica curva de queima "em pico". Para a temperatura de queima mais baixa, $1205^{\circ} \mathrm{C}$, um tempo de patamar de 7 minutos (barras azuis) foi necessário para que a absorção de água exigida fosse atingida. Uma curva de queima a uma temperatura intermediária, de $1210^{\circ} \mathrm{C}$, foi utilizada e, para este caso, foi necessário manter a amostra por 4 minutos no patamar (barras vermelhas). As maiores deformações foram observadas para as barras azuis, referentes à amostra submetida por mais tempo à temperatura de queima. Confrontando-se os resultados com a absorção de água atingida em cada caso, como apresenta a Tabela 2, nota-se um aumento significativo no Índice de Piroplasticidade com a diminuição da temperatura máxima de queima, devido a necessidade de incremento no tempo de patamar utilizado. Enquanto um IP de 46,4 x10-6 $\mathrm{cm}^{-1}$ foi obtido para a curva "em pico", um valor significativamente mais elevado, de $68,1 \times 10^{-6} \mathrm{~cm}^{-1}$, foi calculado para a curva em que maior tempo de patamar é utilizado para compensar a menor temperatura de queima. Assim, maiores temperaturas de queima, que permitam reduções no tempo de patamar utilizado, contribuem para que menores deformações se desenvolvam no produto. Mais de 30\% de redução no IP foi observado com a redução no tempo de patamar do ciclo de queima de 7 minutos para 1 minuto. Em práticas industriais, raramente utilizam-se patamares de 1 minuto. Apesar disso, os resultados sugerem que o máximo de redução possível no tempo de permanência da peça à máxima temperatura de queima deve ser buscado para a redução nas deformações sofridas pelo mesmo.

\section{Efeito do resíduo de moagem}

Para a avaliação de efeito do resíduo de moagem nas deformações piroplásticas sofridas por uma massa de porcelanato técnico, corpos de prova foram prensados a $500 \mathrm{Kgf} / \mathrm{cm}^{2}$ e 7,0\% de umidade, trabalhando-se com dois distintos valores de resíduo: $\mathrm{R}_{\# 325}=5,7 \%$ e $\mathrm{R}_{\# 325}=1,3 \%$. Em função disso, houve uma variação na densidade aparente dos compactos. De $1,86 \mathrm{~g} / \mathrm{cm}^{3}$ para os compactos obtidos do resíduo de moagem de 5,7\%, houve um aumento para $1,89 \mathrm{~g} / \mathrm{cm}^{3}$ no caso da moagem mais refinada. Para compensar tal variação e garantir que a mesma absorção de água, próxima de $0,1 \%$, fosse alcançada para ambas as massas ao final do ciclo, diferentes temperaturas de queima foram utilizadas. Para os corpos de prova com maior densidade aparente foi utilizada uma temperatura de queima de $1215^{\circ} \mathrm{C}$. Para os corpos menos compactados inicialmente, foi necessário o uso de uma temperatura de $1230^{\circ} \mathrm{C}$. Como se observa na Figura 10, a redução no resíduo de moagem acarretou em uma diminuição do índice de piroplasticidade de $66,2 \times 10^{-6} \mathrm{~cm}^{-1}$ para $47 \times 10^{-6} \mathrm{~cm}^{-1}$.

Como observa-se na Figura 11.a, em todas as temperaturas, os corpos de prova produzidos com maior resíduo de moagem (barras vermelhas) apresentam maiores deformações. O principal resíduo de moagem é o quartzo. A redução do resíduo, ou seja, a moagem mais fina da formulação, favorece a dissolução desse

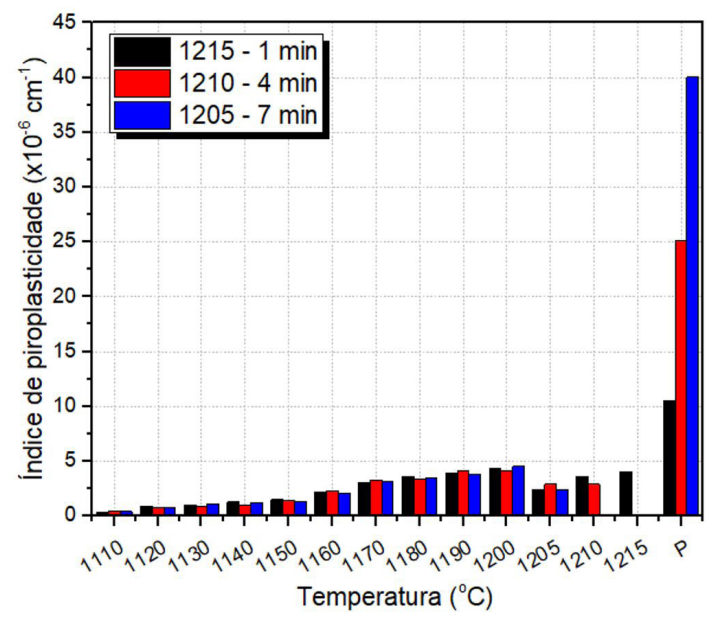

Figura 9 - Evolução do IP durante diferentes ciclos de queima para uma massa de porcelanato, onde $\mathrm{P}$ representa patamar.

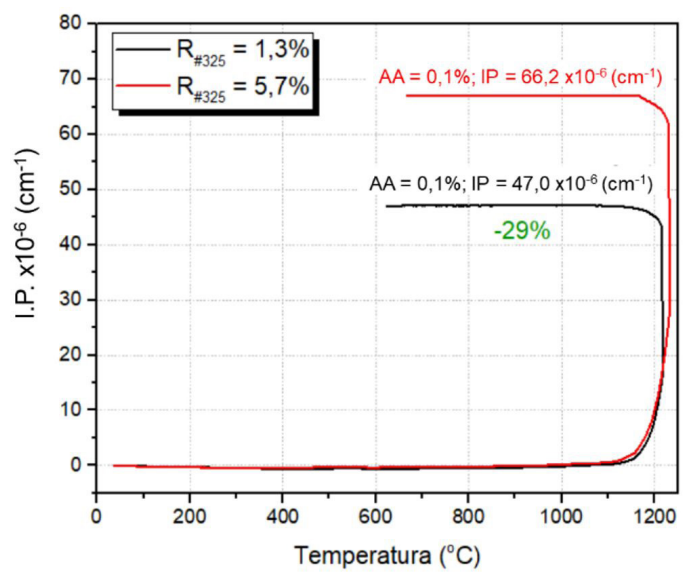

Figura 10 - Efeito da variação do resíduo de moagem no IP de uma massa de porcelanato.

Tabela 2 - Absorção de água e IP para massa de porcelanato submetida a diferentes ciclos de queima.

\begin{tabular}{cccc}
\hline Temperatura $\left({ }^{\circ} \mathbf{C}\right)$ & Tempo patamar $(\mathbf{m i n})$ & Absorção de água $(\%)$ & $\mathbf{I P}\left(\mathbf{x} \mathbf{1 0}^{-\mathbf{6}} \mathbf{c m}^{-\mathbf{1}}\right)$ \\
\hline 1215 & 1 & 0,4 & 46,4 \\
1210 & 4 & 0,4 & 56,5 \\
1205 & 7 & 0,2 & 68,1 \\
\hline
\end{tabular}



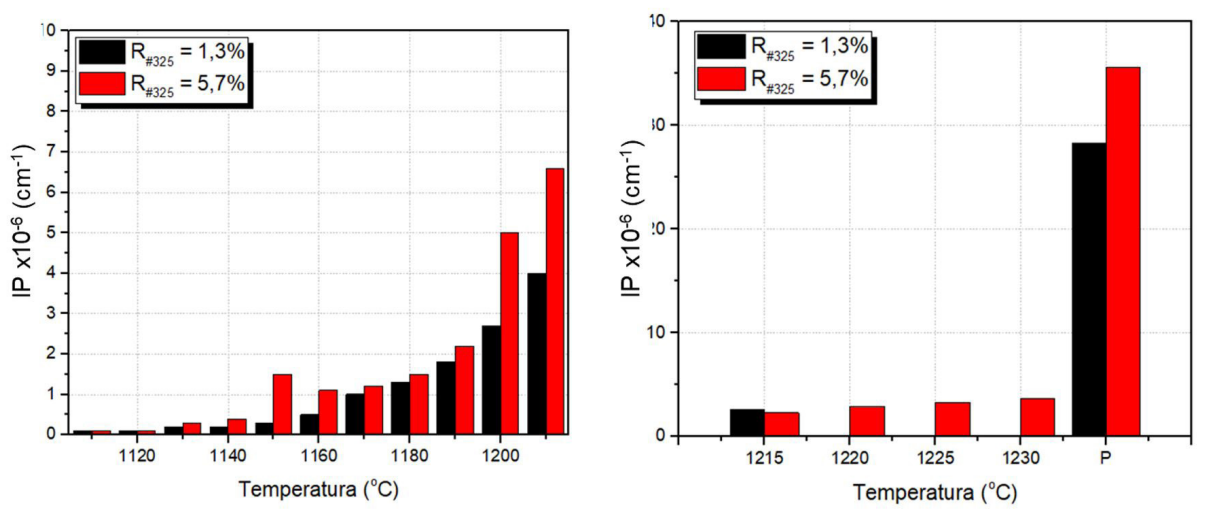

Figura 11- Evolução do IP em função da temperatura para uma massa de porcelanato produzidas com diferentes resíduos de moagem a partir de $1100^{\circ} \mathrm{C}(11 . a)$ e ênfase a partir de $1215^{\circ} \mathrm{C}(11 . \mathrm{b})$

quartzo, mais fino, na fase líquida formada em altas temperaturas, o que faz com que a viscosidade dessa fase aumente. Aumentando-se a dificuldade do fluxo viscoso do líquido, menores as deformações originadas no corpo. A Figura 11.b enfatiza as deformações bastante significativas sofridas nas temperaturas referentes a etapa final do tratamento. Como houve necessidade de queima da massa produzida com maior resíduo de moagem a uma maior temperatura, ao final do processo, todas as deformações manifestadas em temperaturas inferiores são somadas, o que contribui para o maior IP resultante. Assim, para a massa submetida à moagem mais grosseira, tanto a queima em maior temperatura quanto a menor viscosidade do líquido formado, mais pobre em sílica, favoreceu o desenvolvimento de deformações. O resíduo de moagem padrão na produção de um porcelanato técnico é inferior a 2\%. Esses resultados obtidos destacam a importância de se trabalhar com resíduos dentro dessa faixa nas condições industriais de forma a se evitar a formação de defeitos nas peças.

\section{Efeito da densidade aparente}

Utilizando-se um resíduo de moagem fixado em $\mathrm{R}_{* 325}=1,3 \%$ e umidade de prensagem de $7,0 \%$, variou-se a pressão de compactação intencionalmente para produzir corpos de prova com densidades distintas. Foram prensados corpos a $250 \mathrm{Kgf} / \mathrm{cm}^{2}$, que apresentaram densidade aparente de $1,79 \mathrm{~g} / \mathrm{cm}^{3}$, e outros a $500 \mathrm{Kgf} / \mathrm{cm}^{2}$, para os quais a densidade foi incrementada para $1,89 \mathrm{~g} / \mathrm{cm}^{3}$. Quanto maior a densidade aparente da peça, menor o volume de poros a ser eliminado durante a queima para que se atinja a máxima densificação buscada. Para corrigir esse efeito, de forma que os mesmos valores de absorção de água fossem alcançados, diferentes temperaturas de queima foram utilizadas. Os corpos mais compactados foram queimados a $1215^{\circ} \mathrm{C}$ enquanto os de densidade aparente inferior foram queimados a $1220^{\circ} \mathrm{C}$. Em consequência, como se observa na Figura 12, a amostra menos compactada, queimada a $1220^{\circ} \mathrm{C}$, apresentou IP de $70,2 \times 10^{-6} \mathrm{~cm}^{-1}$,

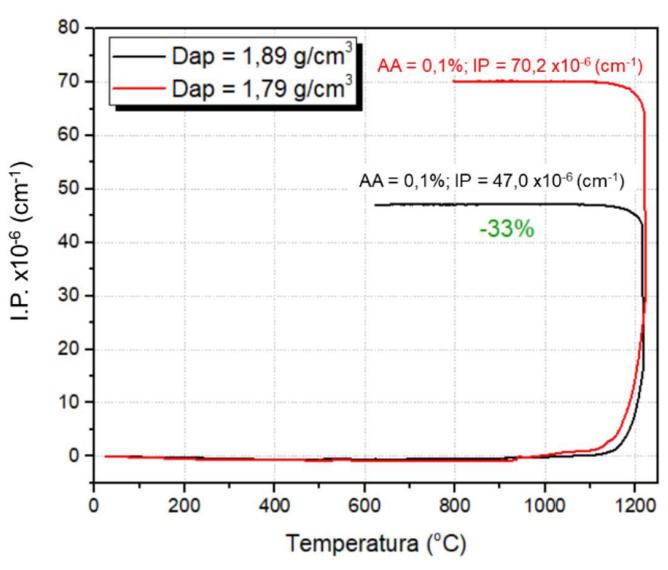

Figura 12- Efeito da variação da densidade aparente no IP de uma massa de porcelanato.

enquanto este índice foi reduzido para $47,0 \times 10^{-6} \mathrm{~cm}^{-1}$ no caso da amostra queimada na temperatura inferior.

A Figura 13.a mostra que em todas as temperaturas analisadas, a peça mais porosa (barras vermelhas, densidade aparente de $1,79 \mathrm{~g} / \mathrm{cm}^{3}$ ) apresenta maiores deformações. $\mathrm{O}$ próprio módulo elástico inferior dessa amostra em relação à mais densa justifica esse resultado. Além disso, há mais espaços vazios para serem preenchidos, havendo necessidade de maior formação de fase líquida e queima em temperatura mais elevada. Como já mencionado na análise do efeito do resíduo de moagem no IP e enfatizado na Figura 13.b, a própria necessidade de queimar a peça em maior temperatura contribui para o aumento das deformações pois somam-se todas as deformações já manifestadas em temperaturas antecedentes, Pelas razões mencionadas, de forma conjunta, o índice de piroplasticidade resultante é significativamente reduzido quando parte-se de uma amostra mais compactada desde o início do processo. Nesse sentido, cabe mencionar que não apenas a pressão de compactação afeta a densidade aparente do corpo verde. Trabalhando-se com a composição 

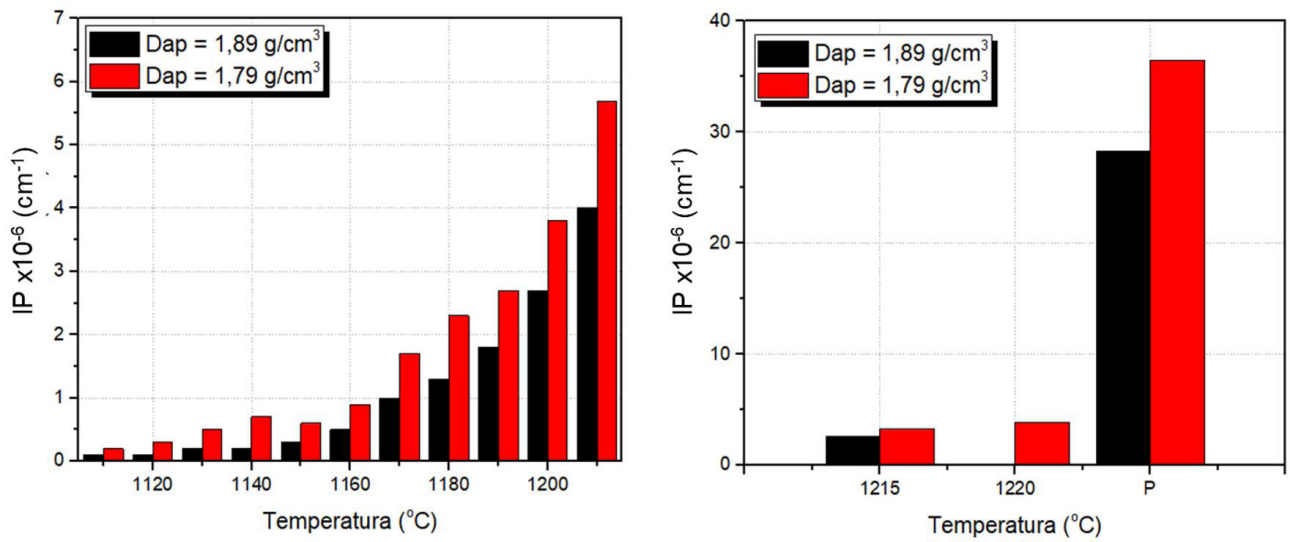

Figura 13- Evolução do IP em função da temperatura para uma massa de porcelanato com diferentes densidades aparentes a partir de $1100^{\circ} \mathrm{C}(13 . a)$ e ênfase a partir de $1215^{\circ} \mathrm{C}$ (11.b)

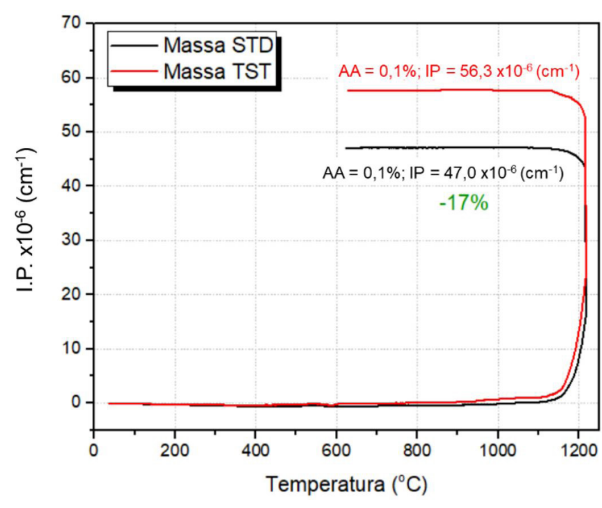

Figura 14 - Efeito da composição da massa no índice de piroplasticidade de um porcelanato.

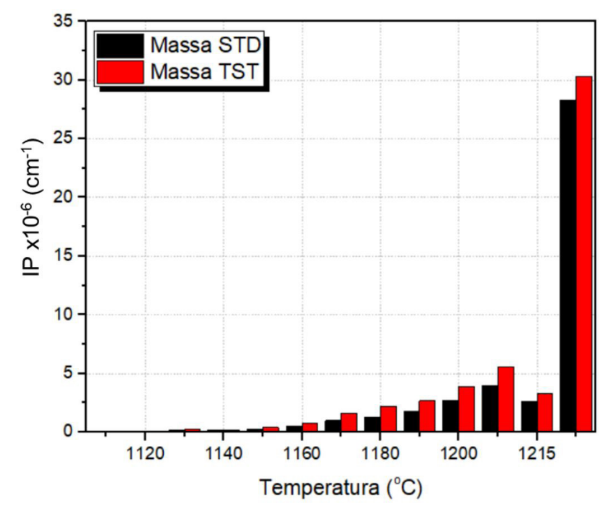

Figura 15- Evolução do IP a partir de $1100^{\circ} \mathrm{C}$ para massas de porcelanato com diferentes composições.

da massa pode-se conseguir um ganho de densidade sem a necessidade no aumento da pressão de compactação.

\section{Efeito da composição da massa}

Nessa etapa do estudo as variáveis de prensagem foram fixadas. Utilizou-se resíduo de $\mathrm{R}_{\# 325}=1,3 \%$, umidade de $7,0 \%$ e pressão de compactação de $500 \mathrm{Kgf} / \mathrm{cm}^{2}$, alterando-se a composição da massa. Em relação à uma massa padrão, adicionou-se, na denominada massa teste, maior fração de óxidos de cálcio e magnésio, agentes formadores de eutéticos. A massa padrão apresentou, inicialmente, densidade aparente de $1,89 \mathrm{~g} / \mathrm{cm}^{3}$, enquanto a massa teste apresentou densidade superior, de $1,93 \mathrm{~g} / \mathrm{cm}^{3}$. Fixou-se a temperatura de queima em $1215^{\circ} \mathrm{C}$ para ambas as massas e o IP ao longo do ciclo de queima pode ser observado na Figura 14. Nota-se que a alteração na composição da massa resultou em aumento no índice de $47 \times 10^{-6} \mathrm{~cm}^{-1}$ para $56,3 \times 10^{-6} \mathrm{~cm}^{-1}$.

Nota-se, ainda, na Figura 15, maior deformação da composição teste em todas as temperaturas representadas. Apesar de essa massa ser menos porosa, o que requer menor quantidade de fase líquida para o preenchimento dos espaços vazios em sua estrutura, a viscosidade da fase formada é inferior devido à presença em maior quantidade de óxidos de cálcio e magnésio. A menor viscosidade desse líquido formado é bastante desejável para o alcance da baixa absorção de água almejada para os porcelanatos pois favorece a cinética de densificação [4]. Entretanto, como apontam os resultados desse trabalho, a formação dessas fases líquidas pouco viscosas é problemática no que diz respeito à deformação das peças durante a queima.

\section{Conclusões}

A etapa inicial do trabalho auxiliou na compreensão do potencial de utilidade do flexímetro ótico para o acompanhamento das deformações sofridas por massas de porcelanato durante a queima. A medição de piroplasticidade em flexímetro ótico oferece maior precisão e permite correlacionar a evolução das deformações aos fenômenos desenvolvidos em diversas faixas de temperatura ao longo do processo. Nesse sentido, constatou-se que a maior parte das deformações se desenvolvem na máxima temperatura do ciclo de queima.

No que se refere às condições industriais estudadas de modo a serem controladas para a redução de defeitos, os resultados apontam que o uso de curvas de queima 
denominadas "em pico", em que as peças permanecem menos tempo à temperatura máxima de queima, favorece a redução das deformações em relação ao uso de patamares mais extensos necessários no caso do uso de temperaturas de queima inferiores.

O resíduo de moagem, a densidade aparente do compacto verde e a composição das massas são outras variáveis estudadas que podem ser controladas industrialmente para a redução da deformação piroplástica. Nesse sentido, devem ser priorizados resíduos de moagem mais baixos, compactações mais elevadas e composições de massas que geram fases vítreas mais viscosas em elevadas temperaturas durante a queima.

\section{Referências}

[1] BANNIER, E. et al. Delayed curvature and residual stresses in porcelain tiles. Journal of the European Ceramic Society, v. 33, n. 3, p. 493-501, 2013.

[2] MELCHIADES, F. G.; ROVERI, C.; SOTÉRIO, J.; SILVA, L. L.; BOSCHI, A. O. Estabilidade das Dimensões e do Formato de Revestimentos Cerâmicos. Parte II: Formato. Cerâmica Industrial, v. 6, n. 6, p. 11-17, nov/dez, 2001.],

[3] BARALDI, LUCA;ACIMAC. World production and consumption of ceramic tiles. Tile International, v. 3, p. 42-48, 2017. ISSN 2039-8301.

[4] RAMBALDI, E. et al. Using waste glass as a partial flux substitution and pyroplastic deformation of a porcelain stoneware tile body. Ceramics International, v. 33, n. 5, p. 727-733, 2007.] 